\title{
OBSERVATIONS ON THE MINOR BASIC HEMOGLOBIN COMPONENT IN THE BLOOD OF NORMAL INDIVIDUALS AND PATIENTS WITH THALASSEMIA
}

\author{
By H. G. KUNKEL, R. CEPPELLINI, U. MULLER-EBERHARD, AND J. WOLF \\ (From the Rockefeller Institute for Medical Research, and Institute for the Study of Human \\ $V$ ariation, and the Department of Pediatrics, Columbia University, N. Y.)
}

(Submitted for publication March 6, 1957; accepted April 11, 1957)

In a previous report (1) a second hemoglobin was described which was found at a concentration of approximately 3 per cent in the blood of normal adult individuals. It was found to resemble hemoglobin $\mathrm{E}$ in electrophoretic properties, but identity with this abnormal hemoglobin was not established. This same component probably had been observed by previous investigators employing the classical Tiselius procedure in occasional specimens of blood from normal persons $(2,3)$ and thalassemia patients (4), but had not been defined as a hemoglobin. The present report describes further properties of this hemoglobin (designated $\mathrm{A}_{2}$ in this paper) with particular reference to its constant presence in the blood of humans and certain primates and its elevation in individuals with thalassemia trait.

\section{MATERIALS AND METHODS}

Blood specimens were usually obtained in acid citrate dextrose or Alsever's solution. Hemolysates were prepared by the method of Drabkin without the use of $\mathrm{AlCl}_{8}$ (1). Following hemolysis the material was subjected twice to high speed centrifugation to insure removal of all red cell ghosts. Special care was necessary in the preparation of the hemoglobin solutions because even a small number of ghosts in clear-appearing solutions interfered in the procedures of electrophoresis employed. The ghosts became adsorbed at the origin, trapping hemoglobin, which then gradually became released during the experiment causing a trail of hemoglobin extending from the origin. Fresh blood samples were routinely converted to carboxyhemoglobin both before and again after the preparation of the hemolysates. This was done by swirling the red cells or hemoglobin solutions under a jet of $\mathrm{CO}$ in a large tube for approximately four minutes. The cyanmethemoglobin derivative was used primarily for older specimens of blood or hemoglobin where partial conversion to methemoglobin had occurred. To each $1-\mathrm{ml}$. sample $0.05 \mathrm{ml}$. of freshly prepared $1 \mathrm{M}$ potassium ferricyanide and $0.05 \mathrm{ml}$ of $1 \mathrm{M}$ potassium cyanide were added.

Normal blood was obtained chiefly from laboratory workers. Material from patients with various diseases was collected from a number of New York hospitals. The specimens from patients with thalassemia were obtained from Italian and Greek individuals in the hematology clinic at the Babies Hospital, Columbia-Presbyterian Medical Center, New York. Five individuals with thalassemia in two families were obtained from index cases at Bellevue Hospital. The great majority of thalassemia trait cases were parents of children with severe Cooley's anemia. In all instances the diagnosis of thalassemia was based on the hematological picture. Several individuals who were suspected of having thalassemia were excluded from the study because of uncertain hematological findings.

Zone electrophoresis was carried out by a slight modification of procedures described previously (5). A broad starch slab, thinner than those usually used, was found most suitable. The following dimensions were employed: 32 by 45 by $0.7 \mathrm{~cm}$. The starch was washed over a filter (with buffer only) prior to use. Barbital buffer $\mathrm{pH} 8.6$ $\Gamma / 20.05$ was routinely employed. The hemoglobin solution was applied to the slab by means of a capillary tube which was inserted in a slit 1 to $2 \mathrm{~cm}$. in length in the starch which was kept just dry enough to prevent fusion of the slit. Numerous specimens could be applied to a single slab in this manner (as many as 30 in three rows in some experiments). Following application of one row of specimens, the slits were fused by means of buffer pipetted carefully on the starch several $\mathrm{cm}$. on either side of the row. A small spatula was used to flatten the site of application. The proper application of the hemoglobin in a thin band required considerable attention to details, but with some experience it was readily possible.

For the demonstration and quantitation of the $A_{2}$ component, the concentrated hemoglobin solutions obtained by the Drabkin technique were used. For the quantitation and clear delineation of the abnormal hemoglobins, the concentrated solutions were diluted with two volumes of buffer. Three-tenths ml. of either the concentrated or dilute solution was usually applied. The starch slab was covered with a polyethylene sheet which was applied with considerable care after blotting the block to remove excess moisture. Too moist a block was avoided because of "melting" of the slab under the pressure of application of the cover. The block was kept so that it would just adhere to the polyethylene under gentle pressure. The sheet was applied in such a manner as to force out most of the air between it and the starch. The 
separation was carried out for approximately 16 hours at 380 volts, giving a current without heating in the vicinity of $85 \mathrm{ma}$. Following the separation, a dry towel was placed at both ends of the block after removal of the cloth contacts to the electrode vessels. This blotting procedure removed excess moisture that accumulated during the separation and facilitated removal of the polyethylene sheet and other manipulations of the starch block. The slab was then carefully viewed over a strong light which caused the red hemoglobin spots to stand out very clearly. In work with the quantitation of the $A_{2}$, this spot was outlined with a thin spatula and the division from the main A component marked. The two segments which included these components were partitioned and removed from the lower polyethylene sheet, and each was packed on a ground glass filter. Distilled water was then added to displace the hemoglobin from the starch. A volume of water slightly greater than the volume of the packed starch was usually sufficient to remove all hemoglobin. With some preparations of starch a few of the smaller particles passed through the filter. These were removed by centrifugation. The main $A$ fraction was diluted to 20 times the volume of the $A_{2}$ fraction and each was measured in a Beckman spectrophotometer at $540 \mathrm{~m} \mu$. The per cent concentration of the $\mathrm{A}_{2}$ component was obtained from these readings employing the dilution factor of 20 . The protein was also determined on the same fractions by means of the modified Folin procedure (5). Hemoglobin $\mathrm{A}$ was used as the standard for these measurements of color and protein concentration. The carboxyhemoglobin color procedure was routinely used but the cyanmethemoglobin method was very helpful in many instances. The two color procedures gave very similar results. When the carbonmonoxy method was used, considerable care was necessary to keep the hemoglobin in the CO form. Partial formation of methemoglobin usually was greater for the $A_{2}$ component and gave low values. Direct protein analysis gave values for the $A_{2}$ component which were 5 to 10 per cent higher than by the hemoglobin color procedures.

TABLE I

Repeated analysis of same hemoglobin solution (normal)

\begin{tabular}{lcc}
\hline \hline \multicolumn{2}{c}{ Hemoglobin $A_{2}$ expressed as per cent of total hemoglobin } \\
\hline & $\begin{array}{c}\text { Same } \\
\text { starch } \\
\text { blocks }\end{array}$ & $\begin{array}{c}\text { Different } \\
\text { starch } \\
\text { blocks }\end{array}$ \\
\hline & 2.41 & 2.51 \\
& 2.51 & 2.33 \\
& 2.18 & 2.45 \\
& 2.11 & 2.98 \\
& 2.36 & 1.92 \\
& 2.93 & 2.51 \\
Mean & 2.42 & 2.75 \\
S.E. & 2.65 & 2.62 \\
Coefficient of var. & 2.56 & 2.51 \\
& $9.9 \%$ & $12.4 \%$ \\
\hline
\end{tabular}

This difference was found to be due primarily to contamination of these preparations with non-colored proteins.

One experiment with a normal hemoglobin solution separated eight times as carboxyhemoglobin on the same starch block is shown in Table I. The results for the same material separated eight times on different starch blocks are also illustrated. In these experiments the results are quite similar. However, there was no question about the greater reproducibility using the same starch slab, and for accurate comparisons this procedure was usually employed.

Antisera for immunological analyses were produced by injecting whole hemoglobin solutions from normal individuals. The Freund adjuvant technique was employed in eight rabbits. Three of these showed weak antibodies against hemoglobin three months after injection. These were re-stimulated by the Freund technique and potent antisera were obtained four weeks after the second injection.

Fetal hemoglobin was measured by the procedure of Singer, Chernoff, and Singer $(6,7)$. Solubility studies were carried out by the procedure described by Green, Cohn, and Blanchard (8).

\section{RESULTS}

\section{Separation of hemoglobin $A_{2}$ from solutions of normal hemoglobin}

Figure 1 illustrates the protein curve obtained after separation by zone electrophoresis of the hemolysate from the red cells of a normal individual. Two colored components are visible-the main hemoglobin $A$ and the small hemoglobin $A_{2}$. The latter is the subject of this report. In addition, a third small peak is observed close to the site of application. This is a colorless component which showed some variation in concentration in different blood specimens and is the main non-hemoglobin protein constituent of the red cells. ${ }^{1}$ The experiment illustrated in Figure 1 was carried out with carboxyhemoglobin and the color of the $A_{2}$ component was clearly visible against the white starch background at the site of the $A_{2}$ protein peak. Figure 2 shows the carboxyhemoglobin color of the hemolysates from the blood of nine normal individuals and two with sickle-cell trait. The $A_{2}$ component is visible in all these specimens. It was also observed in a similar position relative to the main A hemoglobin when oxyhemoglobin,

1 The slowly migrating colorless protein is often elevated in thalassemia and may be confused with hemoglobin $A_{2}$ when protein analyses not involving hemoglobin color are carried out by procedures such as staining of filter paper strips and free solution electrophoresis. 


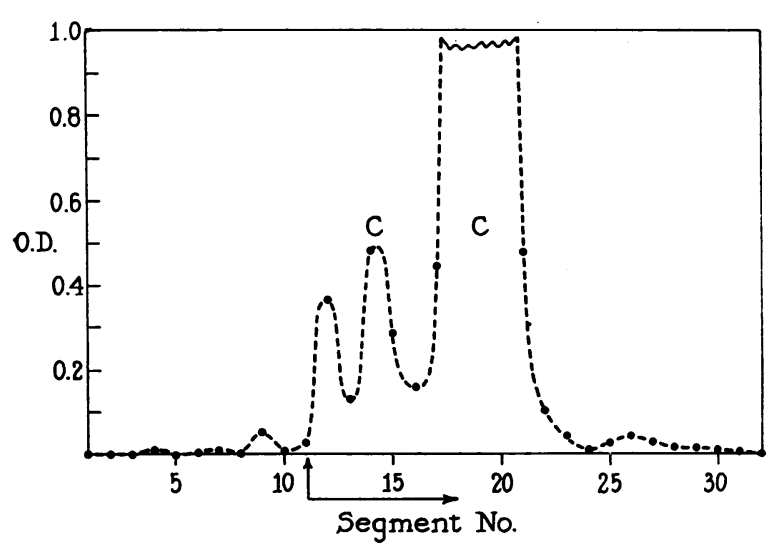

Fig. 1. Protein Curve Obtained After Electrophoretic Separation of the Hemolysate From the Red Blood Cells of a Normal Individual

The two peaks labeled $\mathrm{C}$ were colored. The arrows represent the origin and the migration to the anode.

methemoglobin, and cyanmethemoglobin was used. The color, characteristic of these derivatives, was visible for both the A component as well as the $A_{2}$. The two brown methemoglobin spots were both slightly slower than the corresponding carbonmonoxy derivatives; the port wine colored cyanmethemoglobin spots on the other hand were slightly faster. The $\mathrm{A}_{2}$ component was clearly not a modified form of hemoglobin $A$ due to a different hemoglobin derivative.

In order to rule out the possibility of the anticoagulant playing a role in these studies, preparations of hemoglobin were obtained with heparin, oxalate, citrate and clotted blood. All preparations showed the $A_{2}$ component in approximately the same amount. In addition, different procedures for laking the red cells were employed. The use of water alone without toluene and also simple repeated freezing and thawing followed by centrifugation furnished hemoglobin solutions that all showed the same $A_{2}$ component. In this work the importance of complete removal of the red-cell ghosts prior to separation in the starch became apparent. This was best accomplished through the use of toluene and repeated high speed centrifugation. A red streak extending from the site of application on the starch which obscured the $\mathrm{A}_{2}$ component was observed if all cell ghosts were not eliminated.

Separation by zone electrophoresis was also carried out in a polyvinyl chloride or a paper pulp supporting medium, and the $A_{2}$ component was clearly apparent. . It could also be observed with some difficulty on a filter paper strip particularly after staining the paper. However, the small amount of material that can be applied to the paper strip and the slight trailing of hemoglobin A hampered clear recognition of hemoglobin $\mathrm{A}_{2}$ by this procedure.

Numerous experiments were carried out with hemoglobin $A$ which had been isolated free of $A_{2}$. After salt precipitation, exposure to acid and alkaline $\mathrm{pH}$, treatment with urea and prolonged dialysis and concentration, it was examined by zone electrophoresis. An increase in fast migrating material which formed a streak from the main A peak was frequently observed. However, in no instance was any material formed which resembled the $\mathrm{A}_{2}$ component.

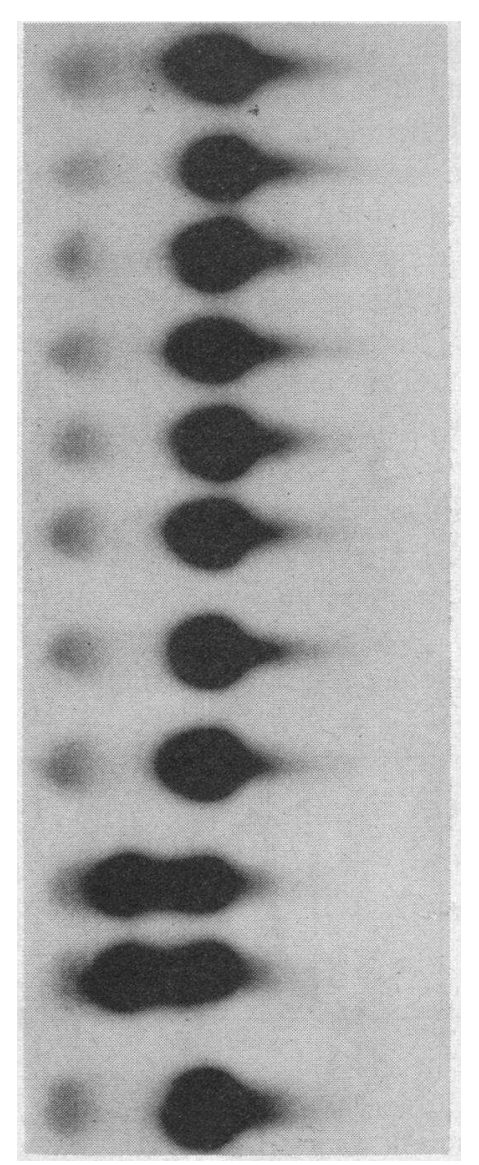

Fig. 2. Photograph of a Broad Starch Block Showing the Red Hemoglobin Components Separated From the Hemolysates Prepared From the Red Cells of Eight Normal Individuals and Two With SickleCell Trait 


\section{Properties of the isolated $A_{2}$ hemoglobin}

The $A_{2}$ component could be readily isolated free from all hemoglobin A by preparative zone electrophoresis. Figure 3 shows the electrophoretic curve obtained for one such preparation after concentration by ultrafiltration. The curve for hemoglobin color closely parallels that for protein as determined by the modified Folin reagent. No peak is visible at the point where hemoglobin $\mathrm{A}$ should appear as indicated from a whole hemoglobin preparation separated on the same starch block. These concentrated preparations of hemoglobin $A_{2}$ also showed from 5 to 10 per cent more protein when compared with hemoglobin $\mathrm{A}$ in terms of hemoglobin color.

Examination of this material in the ultracentrifuge showed essentially one component, although evidence of small amounts of contaminating proteins was obtained following prolonged centrifugation. The $A_{2}$ preparation was compared directly with hemoglobin $A$ in the same experiment and at the same concentration. No difference in sedimentation rate was detectable between the major $\mathrm{A}_{2}$ component and hemoglobin $\mathrm{A}$.

Figure 4 shows the absorption curves for the isolated $\mathrm{A}_{2}$ hemoglobin. These are indistinguishable from those obtained for hemoglobin $\mathrm{A}$ and indicate that the $A_{2}$ component is a true hemoglobin.

Some difficulties were encountered in working with the $A_{2}$ component because of ease of denaturation. If the material were separated in the $\mathrm{CO}$ form and isolated and concentrated in the cold under optimal conditions, it retained the discrete

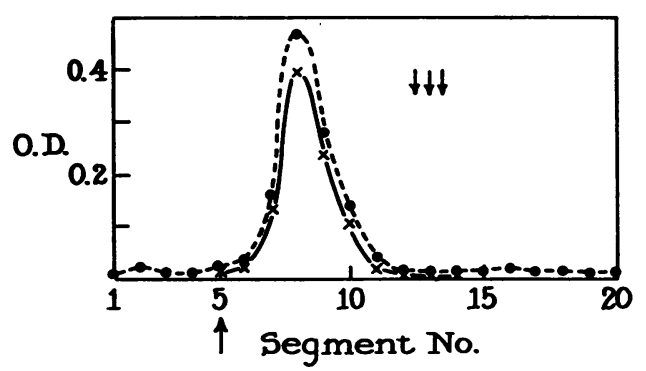

Fig. 3. Protein Curve After Electrophoretic Separation of Isolated $A_{2}$ Component

The three arrows indicate the position $A$ hemoglobin would occupy if present. The dotted line represents Folin color; the solid line carboxyhemoglobin color.

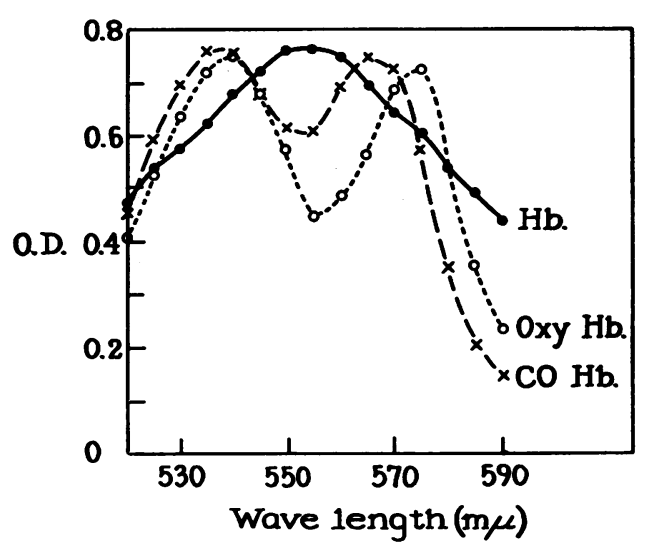

Fig. 4. Absorption Curves Obtained for Various Derivatives of $A_{2}$ Hemoglobin

mobility found in the whole hemoglobin solution. However, on standing even for short periods at $4^{\circ} \mathrm{C}$. alterations were observed frequently and a broader peak was obtained on electrophoresis with slight shifts in mobility. In addition, a large mobility change was occasionally seen for a portion of the $A_{2}$ material; it would show a much slower mobility. This change with resulting double bands was also observed in rare instances when whole hemolysates were separated. These were usually from blood which had been shipped considerable distances. The question of whether hemoglobin $\mathrm{A}_{2}$ represented a single species of hemoglobin was never entirely answered. In some instances the colored bands and the peaks derived from them were broader than might be expected from a single component. However, efforts attempting further separation under varying conditions of $\mathrm{pH}$ and ionic strength in the granular starch medium were unsuccessful. When clear splitting of the $\mathrm{A}_{2}$ band was obtained, it was always due to partial conversion to methemoglobin or some other secondary product. Separation in a polyvinyl chloride medium and also electrophoresis in starch gels ${ }^{2}$ have indicated the presence of a faint hemoglobin band which migrates slightly slower than the main $A_{2}$ component. This has not been isolated and the question of whether or not it represents a derivative of $A_{2}$ hemoglobin remains unanswered.

These alterations and the relatively small amount of material available limited such studies as the determination of solubility. When good

2 Carried out by Dr. A. G. Bearn. 
preparations were employed, the solubility in the ferrohemoglobin form at different ionic strengths of phosphate buffer $(\mathrm{pH}$ 6.8) was close to that for hemoglobin $A$. The curve obtained for $A_{2}$ hemoglobin when these results were plotted in the standard manner was just below that for hemoglobin A, suggesting a slightly lower solubility.

Considerable effort was directed toward the crystallization of the $\mathrm{A}_{2}$ component. When hemoglobin was crystallized by the method of Drabkin from crude hemolysates (one experiment), the $\mathrm{A}_{2}$ component was found at the same concentration as in the original solution. A crystalline preparation obtained through the courtesy of Dr. Drabkin also showed the $\mathrm{A}_{2}$ component at a concentration of 2.5 per cent. These results suggested that $A_{2}$ hemoglobin crystallized in a similar manner to $\mathrm{A}$ hemoglobin. However, the difficulty in detecting other crystal forms at the low concentration of the $\mathrm{A}_{2}$ fraction requires consideration. Attempts were made to crystallize the $A_{2}$ component from fresh preparations isolated by zone electrophoresis. Some crystals were obtained but the double pyramid type characteristic of $\mathrm{A}$ hemoglobin was not observed. For carboxyhemoglobin, fan-shaped, rounded forms were found; whereas for methemoglobin, long thin needles, which frequently grouped into fan-like aggregates, were found. Hemoglobin $\mathrm{A}$ isolated by electrophoresis formed the double pyramids just as in the case of the whole hemoglobin solution. The exact reason for these differences could not be determined. The difficulties involved in the isolation and preservation of $\mathrm{A}_{2}$ hemoglobin must be considered in the interpretation of these results.

An attempt was made to determine if $\mathrm{A}_{2}$ hemoglobin was immunologically different from hemoglobin A. Two different potent antisera against unfractionated hemoglobin reacted strongly with highly purified preparations of both $A$ and $A_{2}$ hemoglobins. Quantitative precipitin curves with the two preparations were very similar. Absorption of one of these antisera with either $A$ hemoglobin or $A_{2}$ hemoglobin removed the antibodies against the other. Analysis by the Ouchterlony plate method showed fusion of the major band for $\mathrm{A}$ and $\mathrm{A}_{2}$ hemoglobins. However, secondary lines appeared with both preparations of hemoglobin, indicating that they were not im- munologically homogeneous. All these experiments pointed to a close immunological relationship between the two hemoglobins.

\section{Distribution of $A_{2}$ hemoglobin in different red cells}

An attempt was made to determine whether $A_{2}$ hemoglobin was present at a constant percentage in all red blood cells or whether it represented the predominant hemoglobin of certain unusual forms. In view of the fact that certain red blood cells show increased osmotic resistance, particularly in individuals with thalassemia where the $A_{2}$ component is elevated, the possibility arose that the cells resisting hemolysis at low-salt concentrations might be high in $\mathrm{A}_{2}$ hemoglobin. Two experiments were carried out, one with cells from a normal individual, the other with cells from a patient with thalassemia trait. In each instance, more than 90 per cent of the cells were hemolyzed. The remaining more resistant cells were then washed with saline and hemolyzed by the usual procedure. Quantitation of the $\mathrm{A}_{2}$ component following electrophoresis indicated a concentration of 2.3 per cent compared to 2.9 per cent for the original whole normal blood, and 5.2 per cent compared to 5.1 per cent for the thalassemia blood. The more resistant cells did not show a higher concentration of the $\mathrm{A}_{2}$ component.

Studies were also performed to determine whether the specific activity of the iron in hemoglobin $\mathrm{A}_{2}$ was the same as that in the main A component at various times following administration of $\mathrm{Fe}^{59}$. Analyses were carried out on the fifth day and on the twelfth day following the administration of $\mathrm{Fe}^{59}$ to a normal individual. The $\mathrm{A}$ and $\mathrm{A}_{2}$ components were isolated free of each other and the radioactivity determined both in terms of $\mathrm{Fe}$ concentration and cyanmethemoglobin color. By each procedure the specific activity was similar for the two components, although in both instances the specific activity was slightly lower for the $A_{2}$ hemoglobin. During the course of these experiments, it was observed that the faster migrating hemoglobin at the front edge of the A peak showed a considerably lower specific activity than the major slower fraction. Since these fractions overlapped it was difficult to determine the exact 
specific activity of $\mathrm{A}$ hemoglobin for comparison with the $\mathrm{A}_{2}$ fraction. Further studies are continuing and will be published in detail separately (9).

\section{IV. $A_{2}$ concentration in normal individuals and various hematological disorders}

Fresh hemoglobin preparations from two individuals, one with a normal and the other with an elevated level of $\mathrm{A}_{2}$ hemoglobin, were examined on seven occasions over a period of four months' time. The $\mathrm{A}_{2}$ component was quantitated in terms of carloxyhemoglobin color, and the values obtained are shown in Table II. This experiment demonstrated that the level of the $\mathrm{A}_{2}$ component was quite constant in the same individual and the variation observed was within the experimental error of the method of analysis.

Tables III and IV summarize the results obtained for the quantitation of the $\mathrm{A}_{2}$ component in 155 different individuals. In each case it was determined by measuring the carboxyhemoglobin color. A mean value of 2.54 per cent was found for normal individuals in this series of cases. Many other normal blood specimens were analyzed but they are not included because they were not as strictly comparable to the pathological specimens. The methods employed varied for these other specimens and cyanmethemoglobin color was often measured. However, in no proven instance was a level below 1.8 per cent or higher than 3.2 per

TABLE II

Repeated analysis of hemoglobin $A_{2}$ from different bleedings of the same two individuals over a six-month period

\begin{tabular}{lcc}
\hline \hline & Normal & $\begin{array}{c}\text { Carrier of } \\
\text { thalassemia } \\
\text { trait }\end{array}$ \\
\hline & 2.41 & 4.51 \\
& 2.35 & 4.80 \\
& 2.42 & 6.03 \\
& 2.18 & 5.53 \\
& 2.13 & 4.61 \\
& 2.36 & 5.12 \\
& 2.55 & 6.52 \\
& 2.61 & 4.82 \\
& 3.42 & 4.66 \\
Mean & 1.11 & 4.54 \\
S.E. & 2.40 & 5.51 \\
Coefficient of var. & $11.5 \%$ & 5.81 \\
& \pm 0.08 & 5.22 \\
& & \pm 0.19 \\
\end{tabular}

cent obtained for normal individuals in either group. Lower values were occasionally found but these were due to selective partial conversion of the $\mathrm{A}_{2}$ component to methemoglobin. When these were checked by the cyanmethemoglobin method, these low values were proved erroneous. No significant difference could be found in the $A_{2}$ concentration for white and Negro individuals. Specimens from five persons of Chinese descent also showed similar $\mathrm{A}_{2}$ levels.

Blood specimens were obtained from 44 patients suffering from various diseases other than thalassemia. Approximately one-half of these came from individuals with assorted blood disorders (Table III). In no instance was an elevation of the $\mathrm{A}_{2}$ component encountered. The mean value of 2.19 with a standard deviation of \pm 0.62 per cent (Table IV) was slightly lower than for the normal group $(p \sim 0.01)$. However, because this represented a very heterogeneous series, a considerably larger number should be studied for a proper comparison. Two low samples, one from a patient with atypical sprue (1 per cent) and the other from a case of idiopathic hemolytic anemia (1.3 per cent), were re-analyzed in triplicate and were clearly lower than normal. Specimens from five patients with iron deficiency anemia were studied. All values were either low or in the normal range.

Thirty-four different individuals with thalassemia trait were studied in regard to the relative concentration of the $A_{2}$ component. Presumptive evidence for this diagnosis was obtained on the basis of a suggestive hematological picture existing in what were considered to be thalassemia families or as parents of children with Cooley's anemia. A mean value of $5.11 \pm 1.36$ was obtained (Table IV). Only two cases in the entire thalassemia series were in the normal range. Both of these were mothers of patients with Cooley's anemia and their hematological picture was compatible with thalassemia trait. Second blood specimens checked the initial findings in both instances. Levels of 2.4 and 2.2 per cent were obtained. One of these individuals was unusual in that she had 14 per cent fetal hemoglobin; in the other case there was 4 per cent fetal hemoglobin. One other individual in a Greek family with thalassemia showed relatively low levels with a mean value at 3.5 per cent (five 
TABLE III

Per cent hemoglobin $A_{2}$ observed in normal and pathological conditions and the number of cases at each $A_{2}$ level

\begin{tabular}{|c|c|c|c|c|c|c|c|c|c|}
\hline$A_{2}$ & Normals & $\begin{array}{c}\text { Thalass. } \\
\text { trait }\end{array}$ & $\begin{array}{c}\text { Thalass. } \\
\text { major }\end{array}$ & $\begin{array}{l}\text { Other } \\
\text { diseases* }\end{array}$ & $A_{2}$ & Normals & $\underset{\text { trait }}{\text { Thalass. }}$ & $\underset{\text { Thalass. }}{\text { major }}$ & $\begin{array}{l}\text { Other } \\
\text { diseases* }\end{array}$ \\
\hline $\begin{array}{c}\% \\
1.0 \\
1.1 \\
1.3 \\
1.4 \\
1.5 \\
1.6 \\
1.7 \\
1.8 \\
1.9 \\
2.0 \\
2.1 \\
2.2 \\
2.3 \\
2.4 \\
2.5 \\
2.6 \\
2.7 \\
2.8 \\
2.9 \\
3.0 \\
3.1 \\
3.2 \\
3.4\end{array}$ & $\begin{array}{l}3 \\
1 \\
3 \\
4 \\
\\
6 \\
7 \\
6 \\
9 \\
6 \\
8 \\
6 \\
3 \\
2 \\
1\end{array}$ & $\begin{array}{l}1 \\
1\end{array}$ & $\begin{array}{l}1 \\
1 \\
1 \\
1 \\
1 \\
1 \\
1 \\
1 \\
1\end{array}$ & $\begin{array}{l}1 \mathrm{w} \\
2 \mathrm{kn} \\
2 \mathrm{df} \\
1 \mathrm{n} \\
3 \mathrm{fko} \\
3 \mathrm{kiv} \\
1 \mathrm{l} \\
4 \mathrm{dkjr} \\
2 \mathrm{gr} \\
2 \mathrm{ho} \\
2 \mathrm{cr} \\
1 \mathrm{u} \\
1 \mathrm{n} \\
4 \mathrm{ekst} \\
5 \mathrm{jjjrr} \\
2 \mathrm{bs} \\
1 \mathrm{q} \\
3 \mathrm{imt} \\
4 \mathrm{ajps}\end{array}$ & $\begin{array}{c}\% \\
3.5 \\
3.8 \\
4.1 \\
4.2 \\
4.3 \\
4.5 \\
4.6 \\
4.7 \\
4.9 \\
5.0 \\
5.1 \\
5.2 \\
5.3 \\
5.5 \\
5.6 \\
5.7 \\
5.9 \\
6.1 \\
6.2 \\
6.4 \\
8.1 \\
9.5\end{array}$ & & $\begin{array}{l}1 \\
1 \\
1 \\
2 \\
1 \\
2 \\
1 \\
3 \\
1 \\
1 \\
2 \\
2 \\
2 \\
1 \\
2 \\
1 \\
2 \\
2 \\
1 \\
1 \\
1 \dagger \\
1 \dagger\end{array}$ & $\begin{array}{l}1 \\
1\end{array}$ & \\
\hline \multicolumn{5}{|c|}{ Totals examined: } & & 65 & 34 & 12 & 44 \\
\hline
\end{tabular}

* Other diseases as follows (in brackets are number of cases observed):

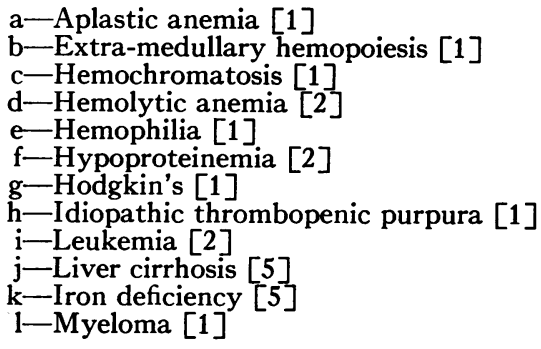

$\dagger$ Thalassemia intermediate.

analyses). The remainder of the cases showed values that were clearly distinguishable from the normal. The highest level was 9.5 per cent (mean of four determinations) in one patient. This 25 year old patient was of interest because he consistently showed extremely high levels of fetal

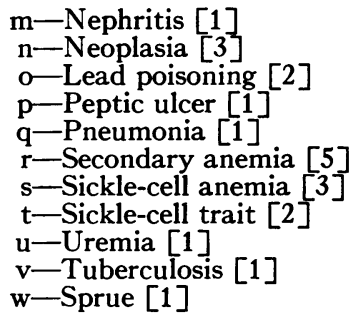

hemoglobin-values ranging from 25 to 55 per cent were obtained. However, he had not required transfusions. Another adult patient with 23 per cent fetal hemoglobin showed 8.1 per cent of the $\mathrm{A}_{2}$ component. Both of these cases with the highest levels had been classified clinically as

TABLE IV

$A_{2}$ levels in different groups of individuals

\begin{tabular}{lccccc}
\hline \multicolumn{1}{c}{ Group } & $\begin{array}{c}\text { No. } \\
\text { examined }\end{array}$ & $\begin{array}{c}\% \boldsymbol{A}_{2} \\
\text { (Mean) }\end{array}$ & $\begin{array}{c}\text { Standard } \\
\text { error }\end{array}$ & $\begin{array}{c}\text { Standard } \\
\text { deviation }\end{array}$ & $\begin{array}{c}\text { Coeff. of } \\
\text { var. }\end{array}$ \\
\hline & & & & & $\%$ \\
Normals & 65 & 2.54 & 0.04 & 0.35 & 13.8 \\
Carriers of thalassemia trait & 34 & 5.11 & 0.23 & 1.35 & 26.5 \\
Thalassemia major & 12 & 2.51 & 0.25 & 0.85 & 33.8 \\
Other miscellaneous diseases & 43 & 2.19 & 0.10 & 0.62 & 28.3 \\
\hline
\end{tabular}


TABLE V

$t$ tests on $A_{2}$ levels in different groups

\begin{tabular}{lcrc}
\hline \hline \multicolumn{1}{c}{ Groups compared } & d.f. & $\mathrm{t}$ & $\mathrm{p}$ \\
\hline Normals vs. thal. trait & 97 & 14.43 & $<0.001$ \\
Normals vs. thal. major & 75 & 0.64 & $>0.20$ \\
Thal. trait vs. thal. major & 44 & 7.12 & $<0.001$ \\
\hline
\end{tabular}

unusual forms of thalassemia possibly of the intermediate type. ${ }^{3}$

Blood specimens from 12 patients with Cooley's anemia were examined (Tables III and IV). The mean level, 2.51, was close to the normal but the variation was considerable with some patients showing elevated levels and others depressed levels. ${ }^{4}$ Five individuals with the double heterozygous condition, sickle-thalassemia, were also investigated. Exact quantitation of the $\mathrm{A}_{2}$ component was difficult in the presence of sickle-hemoglobin. The impression was gained that the $A_{2}$ component was slightly elevated in concentration. It appeared to be normal in concentration in patients with sickle-cell trait (Figure 2) and sicklecell anemia. However, five specimens of human blood were obtained from the umbilical cord of newborn infants. In each case the $\mathrm{A}_{2}$ component was either absent or greatly diminished. One eight day old child who had 81 per cent fetal hemoglobin showed no evidence of the $A_{2}$ component.

\section{Statistical analyses}

The distribution of the $A_{2}$ values among healthy individuals approach normality but for a slight excess of low values. The distribution among carriers of thalassemia trait is also compatible with normality, except for four values mentioned above $(2.1,2.3,8.1,9.5)$, which have only a probability of about 1 per cent of belonging to the same population. These four values are responsible for the higher variance of the thalassemia group in comparison with normals (Table IV). The tests of significance (Table V) show that the differ-

3 Blood from a third patient with an intermediate type thalassemia, kindly furnished by Doctor Hermann Lehmann, showed 10.8 per cent $A_{2}$ hemoglobin.

4 Most of these patients had received transfusions one to six weeks prior to testing, and although fetal hemoglobin was high in all cases, some influence of the transfusions on the $A_{2}$ level appears probable. ence of $A_{2}$ levels between normals and thalassemia carriers is highly significant. Beherens' $d$ tests (10), when the variances of the two groups are significantly different, have given the same results as the $t$ tests. The best discriminating point $x_{\mathbf{E}}$ between these two groups can be calculated according to the procedure of Cavalli (11) using the formula

$$
\mathbf{x}_{\mathrm{E}}=\frac{\mathbf{x}_{1} \sigma_{2}+\mathbf{x}_{2} \sigma_{1}}{\sigma_{1}+\sigma_{2}}
$$

where $\mathrm{x}_{1}$ and $\sigma_{1}$ are the mean and the standard deviation for the thalassemia group; $\mathrm{x}_{2}$ and $\sigma_{2}$ are the mean and the standard deviation for the normals : in our case $x_{E}$ equals 3.09. The formula

$$
\mathrm{t}=\frac{\mathrm{x}_{2}-\mathrm{x}_{1}}{\sigma_{1}+\sigma_{2}}=1.5
$$

permits calculation of the error of classification from the table of probits. For $t$ equals 1.5 , a probability of 94 per cent is found (corresponding to 5 plus $t$ equals 6.5 ). In other words, according to the data herein presented, on the basis of the $A_{2}$ levels only, all individuals with more than 3.1 per cent of $\mathrm{A}_{2}$ can be classified as thalassemia trait. Such a classification has a probability of being correct of approximately 94 per cent.

\section{Observations in other primates and certain animal species}

Five different types of monkeys were investigated in relation to the presence of the $A_{2}$ component. Blood was obtained from 10 chimpanzees and all specimens showed the $A_{2}$ hemoglobin. The picture obtained for these animals was indistinguishable from the human; the mobility of the $A$ and the $A_{2}$ hemoglobin was very similar in the two species (Figure 5). Quantitation of the $A_{2}$ hemoglobin in two of these animals showed a concentration of 2.3 and 2.5 per cent. The South American monkey, Cebus capucinus, also showed the $\mathrm{A}_{2}$ hemoglobin. However, in this case, levels from 4 to 5.5 per cent were obtained in the three animals examined. Numerous Macacus rhesus and cynomolgous monkeys were also studied. In no instance was any $A_{2}$ hemoglobin detectable. The West African green monkey, cercopithecus, also failed to show the $A_{2}$ component in the two blood specimens studied.

No abnormal hemoglobins were encountered in 


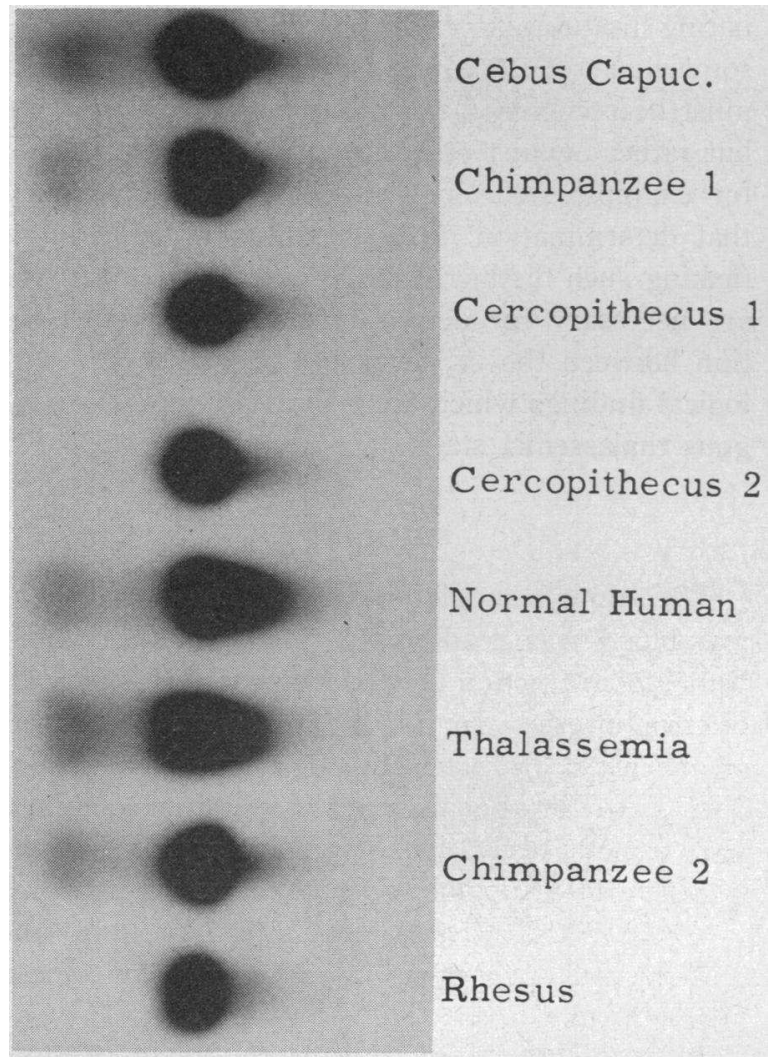

Fig. 5. Comparison of the Hemoglobin Patterns Obtained for the Hemolysates of Humans and Certain Other Primates

The absence of an $\mathrm{A}_{2}$ component in the blood of rhesus and cercopithecus monkeys is noted.

these monkeys except in the case of the cynomolgous type. Here all animals showed a fast hemoglobin in addition to the usual $\mathrm{A}$ hemoglobin. The relative amount of the fast type ranged from 25 to 65 per cent in the six animals studied. Examination of blood specimens from cattle, horses, pigs, dogs and rabbits failed to show a minor hemoglobin component similar to $A_{2}$ hemoglobin.

\section{DISCUSSION}

The properties observed for the $A_{2}$ component in the present study indicate that this hemoglobin is closely related to the main hemoglobin A. The only clearly defined difference is in electrophoretic mobility. Immunologically, the two hemoglobins could not be distinguished. Hemoglobin $\mathrm{A}_{2}$, thus, is not another hemoglobin of the type represented by fetal hemoglobin but appears to resemble the abnormal hemoglobins which also show a close relationship to normal hemoglobin A. It resembles the abnormal hemoglobin $\mathrm{E}$ most closely, but absolute establishment of identity has not been possible. The virtual absence of $A_{2}$ hemoglobin in the blood of newborn infants and its appearance after birth with the decline in fetal hemoglobin is analogous to the situation which has recently been described for hemoglobins S, C and E (12-14).

The significance of the presence of hemoglobin $A_{2}$ in the blood of all normal adult individuals is not apparent. The appearance of the abnormal hemoglobins, which are considered by many workers (15-17) to represent allelic forms of hemoglobin $\mathrm{A}$, does not seem to affect the concentration of the $\mathrm{A}_{2}$ component; normal levels were found both in the heterozygous and homozygous types of sickle-cell disease. This suggests that $\mathrm{A}_{2}$ hemoglobin synthesis is not affected by different mutants of the hemoglobin locus. The occurrence of a hemoglobin similar to the $A_{2}$ component in the blood of certain other primates, particularly the chimpanzee, is of some anthropological interest. The possibility is raised that $A_{2}$ hemoglobin may represent some type of vestigial protein.

Elevation of the $A_{2}$ component is a characteristic finding among individuals with the thalassemia trait. However, low levels were usually found in patients with Cooley's anemia. This is rather surprising when one considers that Cooley's anemia corresponds to homozygosity for the $T h^{T}$ allele, ${ }^{5}$ which in single dose produces the thalassemia trait; a double dose of the mutant gene would also be expected to produce a more extreme effect in respect to the $A_{2}$ level. However, it must be considered that a third type of hemoglobin, namely hemoglobin $F$, is present in the thalassemia homozygotes in amounts varying between 20 per cent and 90 per cent. Because hemoglobin $F$ is probably produced through a metabolic pattern in some way independent of the hemoglobin locus, it may be more pertinent to calculate $A_{2}$ as per cent of the total hemoglobin other than fetal. The values of $\mathrm{A}_{2}$ in $T h^{T} / T h^{T}$ then approach or surpass those in $T h^{T} / T h^{+}$.

A simple genetic explanation of the observed facts concerning the $A_{2}$ hemoglobin is not easily found.

5 For the thalassemia genes, which are usually regarded as not allelic with $H b^{\mathbf{A}}, H b^{s}, H b^{c}$, the mutant allele is indicated as $T h^{T}$ ( $\mathrm{T}$ from thalassemia) and the normal allele as $T h^{+}$. 
It must be realized that $A_{2}$ hemoglobin being present, although at a lower level in normal and $H b^{S} / H b^{S}$ or $H b^{A} / H b^{S}$ genotypes, cannot be regarded as a specific product arising from processes controlled by either the hemoglobin alleles or the $T h^{+}$gene. It could be a by-product of the same metabolic steps which involve the hemoglobin alleles, or it could arise from mechanisms controlled by an entirely different locus. In any case, it is of interest to note that the increase of $\mathrm{A}_{2}$ hemoglobin from the normal level 2.5 per cent to 5 per cent in the $T h^{T} / T h^{+}$is of the same relative magnitude as the two-fold increase of the $\mathrm{S}$ or $\mathrm{C}$ hemoglobins in the $H b^{A} / H b^{S}$ or $H b^{A} / H b^{C}$ heterozygotes when also a $T h^{T}$ allele is present in the genotype. The increase of the abnormal $\mathrm{S}$ or $\mathrm{C}$ hemoglobins from approximately 40 per cent to approximately 80 per cent is explained by regarding the mutant $T h^{T}$ gene as a modifier of dominance upon the alleles at the hemoglobin locus. In the normal homozygote $\left(T h^{+} / T h^{+}\right)$the two alleles, $H b^{A}$ and $H b^{S}$, express themselves almost equally in the phenotype. However, when one $T h^{T}$ is present, hemoglobin S may become completely dominant over hemoglobin A. On the phenogenetic level this means that the metabolic disturbance induced by a $T h^{T}$ gene acts differentially on the relative rates of synthesis of the normal $\mathrm{A}$ and of the abnormal $\mathrm{S}$ or $\mathrm{C}$ hemoglobins. Similarly, it may be inferred that a $T h^{T}$ gene, specifically impairing the syntheses of A hemoglobin, raises the level of the normal $\mathrm{A}_{2}$ hemoglobin in the same way as it modifies the expression of the pathological $\mathrm{S}$ and $\mathrm{C}$ traits; in other words, the metabolic disturbance induced by a $T h^{T}$ gene acts differentially on the relative rates of synthesis of the $\mathrm{A}$ and $\mathrm{A}_{2}$ components.

According to the data collected by Bianco, Montalenti, Silvestroni, and Siniscalco (18), the hematological features most useful for discriminating between normal individuals and thalassemia carriers are in the order: the mean corpuscular volume, the osmotic fragility and the red cell count, with a probability of correctness under optimal laboratory conditions of 98.85 per cent, 98.84 per cent, and 91.90 per cent, respectively (19). Analyses of the data obtained in the present study indicate that the efficiency of the $\mathrm{A}_{2}$ determination (94 per cent) is of the same order. The discrimi- nating usefulness of the standard procedures is somewhat reduced in practice when thalassemia must be recognized not so much against normals but rather against other hematological conditions; for example, deficiency anemias. It seems likely that determination of $\mathrm{A}_{2}$ hemoglobin will aid in making such distinctions, although further studies are necessary for determining the exact correlation between the $\mathrm{A}_{2}$ level and the other hematological findings which are typical for the heterozygous thalassemia state.

\section{SUM MARY}

The minor hemoglobin component $\left(\mathrm{A}_{2}\right)$ of normal blood was readily separated from the main hemoglobin fraction by various procedures of zone electrophoresis. In the isolated form it showed all the usual characteristics of a true hemoglobin. The shifts in the absorption spectrum obtained with various derivatives were similar to those obtained with hemoglobin A. A close resemblance in sedimentation coefficient, solubility, and immunological properties was found for these hemoglobins.

$\mathrm{A}_{2}$ hemoglobin was found in the blood of all of approximately 300 normal adult individuals but was absent or greatly reduced in newborn infants. A similar component was found in the blood of certain other primates, but not in other animals.

Quantitation of the $\mathrm{A}_{2}$ component revealed elevated levels in individuals with thalassemia. A mean level of $5.11 \pm 1.36$ per cent compared to the normal of $2.54 \pm 0.35$ per cent was obtained for a series of 34 carriers of the thalassemia trait. The highest values were obtained in two patients classified as intermediate forms of thalassemia. Children with Cooley's anemia showed considerable variation with most values falling in the normal range.

The possible value of analyses of the $A_{2}$ component in various thalassemia syndromes and their genetic implications are discussed.

\section{ACKNOWLEDGMENTS}

The authors are indebted to Doctor Herbert Hager and Doctor Helen Ranney for some of the hemoglobin samples employed in this study. The advice and assistance of Doctor L. C. Dunn is gratefully acknowledged. 


\section{REFERENCES}

1. Kunkel, H. G., and Wallenius, G., New hemoglobin in normal adult blood. Science, 1955, 122, 288.

2. Stern, K. G., Reiner, M., and Silber, R. H., On the electrophoretic pattern of red blood cell proteins. A preliminary study. J. Biol. Chem., 1945, 161, 731.

3. Sturgeon, P., Itano, H. A., and Valentine, W. N., Chronic hemolytic anemia associated with thalassemia and sickling traits. Blood, 1952, 7, 350.

4. Singer, K., Chapman, A. Z., Goldberg, S. R., Rubinstein, H. M., and Rosenbaum, S. A., Studies on abnormal hemoglobins. IX. Pure (homozygous) hemoglobin C disease. Blood, 1954, 9, 1023.

5. Kunkel, H. G., Zone electrophoresis in Methods of Biochemical Analysis, D. Glick, Ed. New York, Interscience Publishers, 1954, vol. 1, p. 141.

6. Singer, K., Chernoff, A. I., and Singer, L., Studies on abnormal hemoglobin; their demonstration in sickle cell anemia and other hematologic disorders by means of alkali denaturation. Blood, 1951, 6, 413.

7. Singer, K., Chernoff, A. I., and Singer, L., Studies on abnormal hemoglobin; their identification by means of the method of fractional denaturation. Blood, 1951, 6, 429.

8. Green, A. A., Cohn, E. J., and Blanchard, M. H., Studies in the physical chemistry of the proteins. XII. The solubility of human hemoglobin in concentrated salt solutions. J. Biol. Chem., 1935, 109, 631.

9. Kunkel, H. G., and Bearn, A. G., $\mathrm{Fe}^{50}$ studies of the different types of normal hemoglobin. Federation Proc., In press.
10. Fisher, R. A., and Yates, F., Statistical Tables. London, Oliver \& Boyd, 1943.

11. Cavalli, L. L., Delle funzioni discriminanti. Mem. 1st Ital. Idrobiologia, 1945, 2, 301.

12. Schneider, R. G., and Haggard, M. E., Sickling, A quantitatively delayed genetic character. Proc. Soc. Exper. Biol. \& Med., 1955, 89, 196.

13. Thomas, E. D., Motulsky, A. G., and Walters, D. H., Homozygous hemoglobin $\mathrm{C}$ disease. Report of a case with studies on the pathophysiology and neonatal formation of hemoglobin C. Am. J. Med., 1955, 18, 832.

14. Luan Eng, L. I., Postnatal formation of haemoglobin E. Nature, 1956, 178, 1056.

15. Ranney, H. M., Observations on the inheritance of sickle-cell hemoglobin and hemoglobin C. J. Clin. Invest., 1954, 33, 1634.

16. Itano, H. A., Bergren, W. R., and Sturgeon, P., The abnormal human hemoglobins. Medicine, 1956, 35, 121.

17. Neel, J. V., The genetics of human haemoglobin differences: Problems and perspectives. Ann. Human Genet., 1956, 21, 1.

18. Bianco, I., Montalenti, G., Silvestroni, E., and Siniscalco, M., Further data on genetics of microcythaemia or thalassaemia minor and Cooley's disease or thalassaemia major. Ann. Eugenics, 1952, 16, 299.

19. Siniscalco, M., and Smith, C. A. B., The discrimination between normals and microcythaemics as a statistical problem. Proceedings Fifth International Congress Blood Transfusione, Paris, 1954. 